\title{
Corrigendum
}

\section{Corrigendum to: Morphological and molecular characterisation of Hemicriconemoides paracamelliae sp. n. (Nematoda: Criconematidae) and two known species of Hemicriconemoides from China (Nematology 20 (2018), 403-422. DOI: 10.1163/15685411-00003147)}

\footnotetext{
Munawar MARIA ${ }^{1}$, Ruihang CAI ${ }^{1}$, Pablo CASTILlo ${ }^{2}$ and Jingwu ZhenG ${ }^{1,3, *}$

${ }^{1}$ Laboratory of Plant Nematology, Institute of Biotechnology, College of Agriculture \& Biotechnology, Zhejiang University, Hangzhou 310058, Zhejiang, P.R. China

${ }^{2}$ Institute for Sustainable Agriculture (IAS), Spanish National Research Council (CSIC), Campus de Excelencia Internacional Agroalimentario, ceiA3, Avenida Menéndez Pidal s/n, 14004 Córdoba, Spain

${ }^{3}$ Ministry of Agriculture Key Lab of Molecular Biology of Crop Pathogens and Insects, Hangzhou 310058, P.R. China

The above-mentioned paper was submitted with an incomplete address for the authors Ruihang Cai and Munawar Maria. The correct address should be as follows:

Laboratory of Plant Nematology, Institute of Biotechnology, College of Agriculture \& Biotechnology, Zhejiang University, Hangzhou 310058, Zhejiang, P.R. China.
}

\footnotetext{
* Corresponding author, e-mail: jwzheng@zju.edu.cn
} 